\title{
What is the Future for IR Theory? Does it need a Radical Review?
}

\author{
Dana Chelu \\ University of Kent, Canterbury, Kent, CT2 7NZ, United Kingdom \\ Tel: 44-792-873-7652Ｅmail: dc222@kent.ac.uk
}

\begin{abstract}
Contemporary international relations theory is the result of recent works of synthesis with classical political thought, international law, history, and even psychology and biology. While some of these developments, like evolutionary psychology, can prove detrimental to the its development, I find that international relations theory has surpassed most of its moments of crisis, and is characterized more than ever by pluralist thought. Paradigms continue to hold power on researchers, but most of them produce non-paradigmatic theories. It can be concluded that IR theory is still at the beginning (because of the inability of its researchers to draw an accurate view of the discipline itself), we actually observe a positive evolution in the fact that IR is evolving towards a more inclusive and complete science, a science that can offer more answers at practical level, and that the variety of these responses offers a guarantee against their misuse.
\end{abstract}

Keywords: International relations theory, Paradigms, Development, Post-positivism

It is often said that who wants to know the future, must look in the past for answers. This might be the case for the discipline of IR, too. The somewhat troubled history of the last decades, with its fair share of paradigmatic wars, and, more recently, methodological debates, at a first glance, apparently does not allow for too much optimism. In the same time, the 'recent' shift of the discipline in the direction of reconciliation with the political thought and its normative element, and developments of influential IR theories originated in other disciplines, like physics and biology, are complicating our image of the discipline.

What does then the future have in hold for IR? Does the previous bleak image lead us to believe pessimistically in an equally (or even worse) bleak future, or the image we have constructed is inaccurate and we are actually witnessing a coming out of crisis, and an ongoing process of improvement of theory?

There are few resources for determination of prospects in IR theory for the discipline itself, and even fewer studies directed toward a 'prediction' of the future (Davis B. Bobrow, 1999, 2). This is both expected and understandable, since the proper scientific research does not allow for conclusions to be reached without testing the hypothesis, and, as Davis Brobow puts it, because "it fits well with the view of our future as open to choice and purposeful action, with both substantially dependent on recognition of alternatives and conditionalities (Davis B. Bobrow, 1999, 2)". This reluctance justified or not, has prevented theorists to think also about how IR theory should look towards its future. This means not only there are too few attempts to reform the discipline; it has also prevented a coherent evaluation of what we have in the present. Constructing hypothesis about the future of IR theory seems therefore taboo. I agree with Davis Bobrow that working with conjunctures may prove useful to our understanding of the discipline and the directions it should take, even if the conjunctures will never be proven (Davis B. Bobrow, 1999, 2), but I believe we can build a more accurate image of IR just by extracting from present research enough useful information about the direction in which research is headed.

With the exception of the English School and of a few European scholars like Habermas and Raymond Aron, who are more in touch with classical political thought, and are not afraid to employ the normative theory, international relations scholars have mainly axed their research on the above mentioned paradigmatic wars, arriving to a point in time where it became orthodoxy. The most obvious effect was that young researchers were strongly discouraged at a certain point in time during the late 80s to pursue new areas of debate (Maliniak, Daniel, Oakes, Amy, Peterson, Susan and Tierney, Michael J., 2007, 4).

For the purpose of this essay, and also for the space limitation, it is rather unnecessary to review the entire history of the paradigmatic wars. Just in a few words, the paradigmatic wars in the last two decades of the twentieth century were seen to bring to light inter-paradigm intolerance, a failure in admitting the validity of arguments brought by other approaches, the tendency to start and follow fashions, a retreat from science and a disregard of cumulating knowledge (Michael Brecher, 1999, 216-217).

According to Michael Brecher, these were causes for a deeper crisis in IR, one that witnessed the "creation, persistence, 
and accentuation of a set of flawed dichotomies" (Brecher, 1999, 217). What Brecher had in mind for flawed dichotomies were the reliance of researchers exclusively on theoretic work, and the exclusion of history from their research, the overwhelming use of deductive paths to theory and the predominance of quantitative methods in research (Brecher, 1999, 218). But Brecher also witnessed the beginning of change, in the reconciliation between theory and history, in the success of inductive research such as the Singer's COW Project, and in the combination of research techniques (Brecher, 1999, 219-221). Michael Brecher provides an alternative to the deductive path, in what he calls a bottom-up strategy, where variables are first analyzed and classified, then grouped, creating a model that contributes to the creation of theory (Brecher, 1999, 223). Brecher is actually giving account of his own work in the ICB Project, and concludes that pluralism and synthesis are the proper paths to future research (Brecher, 1999, 228). He also bemoans the overwhelming use of rational choice theory, arguing that it has a reductionist, unilateral character, and that it disregards the fact that human decision-makers are incapable of "pure rationality"(Brecher, 1999, 231).

Another useful critique of rational choice theory was given by Raymond Aron, who (as Bryan Frost observes), denied the existence of an universal purpose for all states (Bryan-Paul Frost, 2006, 510), such as power or national interest, and, as a consequence of this, the inability of international relations theorists to predict the behaviour of the states in cases of crisis. Aron's dismissal of such a concept, which Frost compares to the "utility" (Frost, 2006, 511), in economics, is not only a critique against realism, but also a critique of the entire discipline that rejects the notion of justice (Frost, 2006, 513). What Aron means is actually the states' own conception of justice, which differs from unit to unit, and that conditions the strategy employed as such (Frost, 2006, 515). The result of Aron's research is that states which share the same conception of justice create stable systems (Frost, 2006, 515), a conclusion which will be also reached by scholars combining International Law and International Relations theory, as it will be detailed below. But, as Frost shows, Aron's work is not limited to critique, but also provides directions for the reconciliation of IR theory with the Political Thought, as well as with history (Frost, 2006, 516-517).

Coming back to our issue, the future of IR theory, we need to focus on the determination of fractures in the present. Is Brecher's image (chronologically the most recent among those analyzed above) still valid, or have things evolved, and we do not need to worry? First of all, paradigmatic wars have become a thing of the past. Scientific evidence shows that non-paradigmatic studies account for more than $50 \%$ of all the articles appeared in the most influential academic journals. As a recent TRIP research project has determined "the steady increase in non-paradigmatic articles from 30 percent in 1980 to 50 percent in 2006" (Maliniak, Oakes, Peterson, and Tierney, 2007, 8). Other evolutions included the disappearance of non-theoretic work: "the dramatic decline of atheoretic work from 47 percent in 1980 to 7 percent in 2006, the emergence of constructivism in the early 1990s, the prominence of liberalism relative to the other three major paradigms throughout the time series, the complete collapse of Marxist work starting in 1982 (8 percent) until 1991 (under 1 percent). The collapse of the Marxist paradigm in IR precedes the collapse of the Soviet Union and the end of the Cold War" (Maliniak, Oakes, Peterson, and Tierney, 2007, 8). But the most striking find is that realism has occupied only a minor, and in continuing decline, place in the field, throughout the entire period researched by the TRIP Project (Maliniak, Oakes, Peterson, and Tierney, 2007, 8). Also, International Relations theory has made important steps toward reconciliation with other disciplines, like political thought, history, and international law. Research on the methodological tools used recently by IR theorists, shows that, although the most used method is the quantitative one, it is almost in all cases combined with other methods of research.

Therefore it seems Brecher's concerns should not be reiterated for the future of the discipline. Why then some authors bemoan them still? Are they the only ones out of date, or is it a larger phenomenon which contributes to the maintenance of old debates? According to TRIP Project research, even though articles appeared in the leading journals have dealt less and less with paradigmatic subjects, statistics show that, at least in the United States, researchers not only choose to view themselves as belonging to various paradigms, but they also contribute to the myth of the paradigmatic wars, by attributing them a larger proportion than TRIP research shows: "The survey evidence reveals that IR scholars believe the literature is dominated by work that fits within one of the major paradigms, and this is not surprising since we have been telling each other and our students for years that realism and liberalism (and to a lesser extent constructivism and Marxism) are the organizing paradigms of the discipline. The conventional wisdom claims that realism was dominant in the 1980s and that the end of the Cold War led to the collapse of Marxism, the decline of realism, and the rise of liberalism and constructivism. Indeed, this is largely what the survey data show. Today, despite a clear decline in IR scholars' perception of the importance of realism, they believe that nearly 30 percent of the literature is still realist in orientation. IR scholars' perception of the percentage of literature devoted to liberalism has also declined, but faculty believe that nearly 27 percent of today's IR literature can be categorized as liberal. The proportion of literature perceived to build upon constructivism has risen over time, according to faculty respondents, from 10 percent in the 1980 s to a high of 25 percent in the 1990s before levelling off at 17 percent today" (Maliniak, Oakes, Peterson, and Tierney, 2007, 8).

And this is manifested predominantly in the large proportion dedicated by introductory courses in international relations to paradigms, especially to realism, which statistics shows actually to have lost the hegemony of international relations 
theory since before 1980, the earliest year taken into consideration by the TRIP Project. From the data presented by TRIP authors, it results that researchers in America still see the discipline in a very traditional way, a view that does not correspond to reality anymore. In my opinion, time will contribute gradually to the disappearance of this false image, so it does not represent a concern for the future of international relations theory.

In 1989, Jim George analyzed the discipline and found it dominated by dissent among the older schools and new developments, such as the "'critical theory', 'post-positivism', 'discourse analyses', or 'post-structuralism"' (George, Jim, 1989, 270). According to Jim George, there are four challenges to the orthodoxy of IR theory: "the first emphasizes the inadequacy of the positivist/empiricist approach to the study of human society and politics. The second, concerning the process by which knowledge is constituted, stresses social, historical, and cultural themes rather than those reliant on "cogito" rationalism, notions of autonomous individualism, or variants on the "sense data" or "correspondence rule" formats. The third rejects as futile the foundationalist search for an objective knowledge external to history and social practice. The fourth emphasizes the linguistic construction of reality" (George, Jim, 1989, 272). But, at that time, as Jim George puts it, optimism was premature, because any attempts to reform the discipline were met with widespread resistance (George, Jim, 1989, 275). The merit of the third debate was that to introduce alternatives to orthodox IR, and its legacy is represented by the wave of recent developments that sought to improve IR and that build bridges between IR and other disciplines.

It has became obvious that IR theory cannot continue on its own to describe accurately and in a scientific manner a world in change, where the boundaries between domestic and international are beginning to erode. This is far from being a novelty within the political thought, as Howard Williams concludes when analyzing Lenin's essay on "Imperialism" (Williams, Howard, 1994, 136). The analysis entitles Williams to conclude that the relation between IR theory and Political Thought is necessarily a symbiotic one (Williams, 1994, 137), since the individual has outgrown its position of subject to one country to citizen of the world, empowered, as Rosenau would say, by the recent technological advances (Williams, 1994, 139).

There have also been attempts to synthesize the findings of international law with International Relations theories. While most of the merit for this approach resides with the exponents of international law, the combined effort of the two disciplines is focused on explaining that anarchy at supranational level is not a synonym with "disorder and conflict: it merely means that there is no effective supranational authority" (Sriram, Chandra Lekha, 2006, 470). Sriram shows the beneficial outcomes of research between these two disciplines in practice, especially in the cases where there are post-atrocity justice problems (Sriram, 2006, 473).

If the discipline has made a lot of progress in the last years, thanks to reformers like the exponents of the English School, it is still obstructed by the resilience of researchers towards the normative theory, and the reconciliation of international relations theory with the political thought. In the efforts to construct the discipline, researchers often resorted to a scientific language that was intended to provide the research with increased explanatory value, and in the same time to avoid any moral implication (Rengger, Nicholas, 2000, 756). I think the cause for this intolerance towards morality resides in the attempts to establish the discipline as an objective science, and to distance it from political science, but objectivity was taken too far. As Rengger shows, Morgenthau was the first to launch an attack towards this tendency, but in time the result was that realism was credited with the strongest intolerance towards morality in international relations theory (Rengger, Nicholas, 2000, 757). The efforts of Wight and Butterfield to reform the discipline, as Rengger says, were largely unsuccessful. Recent attempts to re-introduce morality within international relations theory were done by Walzer and Beitz, and the establishment of the critical international theory, the findings of the Frankfurt School, and the contribution to liberal/democratic peace thesis (Rengger, Nicholas, 2000, 761) are part of the solution and are evidence for a definite shift within the discipline.

The same blurriness of borders between IR theory and Political Thought is discussed by Brian C. Schmidt. He identifies not one, but three areas where reunification is visible: "normative theory, democratic theory and work that can be placed in the rubric of identity/difference" (Schmidt, Brian C. 2002, 116). He also finds that not only IR theory is incomplete without the Political Thought, but also the reverse is true, agreeing with David Held, and before Martin Wight, that Political Thought theory is incomplete without taking into account the global system (Schmidt, 2002, 119). Schmidt also analyzes the work of David Held on democratic theory within the context of the reunification of IR theory with Political Thought, who asserts that many of the characteristic features of democracy "majority rule, accountability, autonomy, legitimacy, consent, self-determination - are rendered increasingly inoperable by forces operating under, above and through the sovereign state" (Schmidt, 2002, 127). Held's conclusion is that democracy itself is under question (Schmidt, 2002, 127). Both Held's and Schmidt's work are useful reference points if we are to prove the value of the reunification/reconciliation between IR and PT, and the progress both disciplines are making from this association.

Progress within the discipline is therefore the result of recent works of synthesis with Political Thought, with International Law, with History. Another attempt to increase the scientific prestige of the discipline was the use of 
biology in the creation of bodies of theory like the evolutionary concepts and the complexity theory (Bell, Duncan, 2006, 497). These contributions are welcomed, as long as they do not attempt to give universal answers derived from biology to IR issues, like for example evolutionary psychology. Duncan Bell shows that development of this fatalistic body of theory is dangerous because it of its attempts to explain important IR dilemmas through genetic determination theories (Bell, 2006, 498-499), while disregarding the role of "culture, social structures and political institutions" (Bell, 2006, 499). By declaring many of the problems (such as racism, nationalism, violence, etc.) faced by the international society as genetic derived, the exponents of EP create the idea it is impossible to change the state of facts (Bell, 2006, 505). Furthermore these arguments can be employed in various purposes (Bell, 2006, 507). If such theories get to conquer ground within international relations theory, they will prove detrimental to the discipline in the same measure extremist theories.

From what we have seen so far, the discipline of IR has surpassed most of its moments of crisis, and is characterized more than ever by pluralist thought. Researchers are engaged in producing mostly non-paradigmatic theories, even though they continue to believe in the force of paradigms.

While from some aspects, we denote that IR theory is still at the beginning (because of the inability of its researchers to draw an accurate view of the discipline itself), we actually observe a positive evolution in the fact that IR is evolving towards a more inclusive and complete science, a science that can offer more answers at practical level, and that the variety of these responses offers a guarantee against their misuse.

\section{References}

Bell, Duncan. (2006). Beware of false prophets: biology, human nature and the future of International Relations theory, International Affairs 82, 3 493-510.

Bobrow, Davis. B. (Summer, 1999), Prospecting the Future, International Studies Review, Vol. 1, No. 2, Prospects for International Relations: Conjectures about the Next Millennium, 1-10.

Brecher, Michael. (June, 1999), International Studies in the Twentieth Century and beyond: Flawed Dichotomies, Synthesis, Cumulation: ISA Presidential Address, International Studies Quarterly, Vol. 43, No. 2, 213-264.

Frost, Bryan-Paul. (Sept. 2006), Better Late Than Never: Raymond Aron's Theory of International Relations and Its Prospects in the Twenty-First Century, Politics \& Policy, Vol. 34, No. 3, 506-531.

George, Jim. (Sep., 1989), International Relations and the Search for Thinking Space: Another View of the Third Debate, International Studies Quarterly, Vol. 33, No. 3, 269-279.

Maliniak, Daniel., Oakes, Amy., Peterson, Susan. \& Tierney, Michael. J., (August/ September 2007), The International Relations Discipline, 1980-2006, Prepared for the Annual Meeting of the American Political Science Association, Chicago Illinois, http://mjtier.people.wm.edu/TRIP.pdf.

Rengger, Nicholas. (2000), Political Theory and International Relations: Promised Land or Exit from Eden? International Affairs, 76, 4, 755-770.

Schmidt, Brian. C. (April 2002), Together again: reuniting political theory and international relations theory, British Journal of Politics and International Relations, Vol. 4, No. 1, 115-140.

Sriram, Chandra. Lekha. (2006), International law, International Relations theory and post-atrocity justice: towards a genuine dialogue, International Affairs 82, 3 467-478.

Williams, Howard. (1994), International Relations and the Reconstruction of Political Theory, Politics, 14(1) 135-241. 